\title{
Epidemiology of Stone Disease
}

\author{
Gary C. Curhan, MD, ScD \\ Associate Professor of Medicine, Channing Laboratory and Renal Division, Department of Medicine, \\ Brigham and Women's Hospital and Harvard Medical School, Boston, MA; Associate Professor of \\ Epidemiology, Harvard School of Public Health, Boston, MA
}

\section{Abstract}

Epidemiology has improved our understanding and management of stone. These types of studies have quantified changes in patterns and burden of disease, while identification of risk factors has changed clinical practice and provided insight into pathophysiologic processes related to stone formation. Because nephrolithiasis is a complex disease, an understanding of the epidemiology, particularly the interactions among different factors, may help lead to approaches that reduce the risk of stone formation.

Epidemiology is defined as the study of the distribution and determinants of disease. Epidemiology can help with the understanding and management of stone disease in several ways. First, epidemiologic studies can quantify changes in patterns and the burden of disease. Second, identification of risk factors in large epidemiologic studies may provide insight into pathophysiologic processes related to stone formation. Third, these types of studies allow examination of the interaction between factors, such as different dietary factors or geneenvironment interactions. Because nephrolithiasis is a complex disease, an understanding of the epidemiology, particularly the interactions among different factors, may help lead to approaches that reduce the risk of stone formation.

\section{Prevalence}

Stone disease is common with the lifetime risk of stone formation in the US exceeding $12 \%$ in men and $6 \%$ in women[1,2]. However, the prevalence of nephrolithiasis, defined as a history of stone disease, varies by age, sex and race. The prevalence appears to have increased in the last quarter of the $20^{\text {th }}$ century for men and women, black and whites[2] (See Figures 1 and 2). While this increase may be real, another possibility is that it was due to increased detection of asymptomatic stones due to the increasing use and sensitivity of imaging studies. Prevalence of stone disease has also increased in other parts of the world including Japan[3] and Germany [4].

Stone disease prevalence within the US varies by racial background[2,5]. A history of stone disease is most common among older white males ( 10\%), and lowest in younger black females $(\sim 1 \%)$. The prevalence in Asians and Hispanics falls somewhere in between.

Corresponding author for proof and reprints: Gary C. Curhan, MD, ScD, Channing Laboratory, Brigham \& Women's Hospital, 181 Longwood Avenue, Boston, MA 02115, (617) 525-2683, (617) 525-2008 (fax), E-mail: Gary.Curhan@ channing.harvard.edu (email).

Publisher's Disclaimer: This is a PDF file of an unedited manuscript that has been accepted for publication. As a service to our customers we are providing this early version of the manuscript. The manuscript will undergo copyediting, typesetting, and review of the resulting proof before it is published in its final citable form. Please note that during the production process errors may be discovered which could affect the content, and all legal disclaimers that apply to the journal pertain. 
Prevalence of stone disease also varies by geographic location within the US. A study of over 1 million individuals found a north-south and west-east gradient such that the highest prevalence of stone disease occurred in the Southeastern US[6].

\section{Incidence}

Several population-based studies have demonstrated that incidence rates, defined as the onset of an individual's first kidney stone, vary by age, sex and race. As with prevalence, the incidence rates are highest in white males. For men, the incidence begins to rise after age 20, peaks between 40 and 60 years at $\sim 3 / 1000 / y r$ and then begins to decline[1,7,8]. For women, incidence rates seem to be higher in the late 20 's (2.5/1000/yr) and then decreasing to $1 / 1000$ / yr by age 50 . This rate then appears to remain relatively constant for the next several decades $[1,8-10]$.

Although earlier studies suggested that incidence rates were rising in the US, a recent study from Rochester, Minnesota suggests that this trend may be changing. Using the same methodology as a study done 30 years earlier that showed increasing incidence rates in men and women between 1950 and 1974, the recent study found that the incidence rates since 1990 may be falling in men and have reached a plateau in women[11].

\section{Recurrence rates}

Early reports suggested that if left untreated the likelihood of forming another stone after the initial episode was 30 to 40 per cent at 5 years [1]. These figures from observational studies are similar to the recurrence rates in the control arms of recently published randomized trials $[12,13]$. Encouragingly, the treatment arms of many of the randomized trials have shown dramatic reductions in recurrence rates by $50 \%$ or more[12-15]. These reductions by medication or dietary interventions emphasize that recurrent stone disease is preventable.

\section{Risk factors}

Our understanding of the risk factors for stone formation has increased substantially over the past several decades. Risk factors are generally divided into non-dietary, dietary and urinary.

\section{Non-dietary}

Family history-The risk of becoming a stone former is more than 2.5 times greater in individuals with a family history of stone disease[16]. This higher risk is likely due to a combination of genetic predisposition as well as similar environmental exposures (e.g. diet). A polygenic inheritance has been proposed to account for the tendency to calcium oxalate stone formation in families[17]. While a number of genetic factors have been clearly associated with rare forms of nephrolithiasis, information is still limited on genes that contribute to risk of the common forms of stone disease.

Systemic disorders-Although nephrolithiasis has traditionally been considered a renal disorder, there is overwhelming evidence that it is in fact a systemic disorder. Primary hyperparathyroidism, renal tubular acidosis and Crohn's disease are well-described conditions that increase the risk of formation of calcium containing stones. Primary hyperparathyroidism may be found in $5 \%$ of stone formers[18].

More recently, a number of other common conditions have been convincingly linked to nephrolithiasis. Increasing body size as assessed by weight, body mass index or waistline is associated with an increasing risk of stone formation independent of other risk factors including diet[19]. The magnitude of the increase in risk from BMI is higher in women than in men. For 
example, the risk of stone formation for individuals with a BMI $\geq 30 \mathrm{~kg} / \mathrm{m}^{2}$ compared to those with a BMI 21-23 was 30\% higher among men but nearly two-fold higher among women. Weight gain also increases the risk of stone formation. A 35 pound weight gain since early adulthood increased risk of stone formation by $40 \%$ in men and $80 \%$ in women. The mechanism (s) for the increased risk associated with larger body size is unknown at present.

A history of gout increases the likelihood of forming kidney stones, both uric acid and calcium oxalate. In a national health survey, individuals with gout were $50 \%$ more likely to have a history of stones[20]. When examined prospectively, a history of gout was associated with a doubling of the risk of forming a stone, independent of diet, weight and medications[21]. Although the mechanism for this relation is unknown, possibilities include insulin resistance and acid-base defects.

More recently, diabetes mellitus was found to raise the risk of stone formation, independent of diet and body size[22]. Cross-sectionally, individuals with a history of type II DM were more than $30 \%$ more likely also to have a history of nephrolithiasis. Prospectively, a history of type II DM increased the risk of stone formation by $30-50 \%$ in women but not in men.

Environmental factors-Individuals working in a hot environment appear to be at higher risk for stone formation[23]. In many situations, lack of access to water or bathroom facilities may lead to lower fluid intake and thus, because of lower urine volume, a higher risk of stone formation.

\section{Dietary Factors}

The composition of the urine is influenced by dietary intake and several dietary factors have been proposed to modify the risk of nephrolithiasis. Nutrients that have been implicated include calcium, animal protein[24], oxalate[25], sodium[26], sucrose[27], magnesium[28], and potassium[29]. Because patients who develop stones often change their diet, studies that retrospectively assessed diet may be hampered by recall bias. Other studies have examined the relation between diet and changes in the lithogenic composition of the urine, often using calculated relative supersaturation. However, the composition of the urine does not completely predict risk and not all the components that modify risk are included in the calculation of supersaturation (e.g. urine phytate). Thus, prospective studies are best suited for examining the associations between dietary factors and risk of actual stone formation.

Calcium-The first prospective study of dietary factors and the risk of incident stone disease was performed in a cohort of more than 50,000 male health professionals aged 40 to 75 years at baseline[7]. Although dietary calcium had been strongly suspected of raising the risk of stone disease, men with a higher intake of dietary calcium actually had a lower risk of incident nephrolithiasis independent of other risk factors. This inverse association has been confirmed in two other prospective studies in women[9,10] and in an updated analysis in men[30]. Although the mechanism of this effect is unknown, low calcium intake is known to increase oxalate absorption and urinary excretion[31], and individuals with lower calcium intake have lower 24 hour urine oxalate excretion. While the reduction in risk due to higher dietary calcium intake may be due to reducing urine oxalate, it is also possible that there is some other protective factor in dairy products (the major source of dietary calcium in the US). A subsequent study showed that low dietary calcium intake may increase the risk of stone formation, even among individuals with a family history of stones[16].

The above mentioned observational data were subsequently confirmed in a randomized trial by Borghi and colleagues that compared a low calcium diet $(400 \mathrm{mg} / \mathrm{d})$ to a diet containing $1200 \mathrm{mg}$ of calcium along with low sodium and low animal protein intake in men with hypercalciuria and calcium oxalate stones[12]. The rate of recurrence was reduced by $50 \%$ in 
the higher calcium intake group. While some authorities still question whether a high calcium diet reduces the risk of stone formation, there is overwhelming evidence that calcium restriction is not beneficial and may in fact be harmful, both for stone formation and bone loss.

Despite similar bioavailability, the impact of supplemental calcium appears to be different from dietary calcium. In an observational study of older women, calcium supplement users were $20 \%$ more likely to form a stone than women who did not take supplements, after adjusting for dietary factors[9]. In younger women and men, there was no association between calcium supplement use and risk of stone formation[7,10]. The discrepancy between the risks from dietary calcium and calcium supplements may be due to the timing of calcium intake. In these studies, calcium supplements were often taken in between meals, which would diminish binding of dietary oxalate. The recently published Women's Health Initiative randomized trial also demonstrated a $17 \%$ increased risk of stones with calcium supplementation[32]. However, these results should be interpreted cautiously as the participants were instructed to take their supplements with meals, and the supplements contained both calcium and vitamin D.

Oxalate-The role of dietary oxalate in the pathogenesis of calcium oxalate nephrolithiasis is unclear[33]. The proportion of urinary oxalate derived from dietary oxalate is controversial; estimates range from 10 to 50\%[33]. In addition to the GI absorption of dietary oxalate, urinary oxalate is also derived from the endogenous metabolism of glycine, glycolate, hydroxyproline, and vitamin C. Due to variable and often low bioavailability, much of the oxalate in food may not be readily absorbed. The dietary contribution of urinary oxalate may be higher in stone formers. Up to one-third of patients with calcium oxalate nephrolithiasis may have increased absorption of dietary oxalate, and in some cases a deficiency of oxalate degradation by the bacterium Oxalobacter formigenes in the gut could be the culprit[33]. The impact of dietary oxalate on risk of stone formation has not yet been studied prospectively because of the lack of sufficient and reliable information on the oxalate content of many foods. However, recent reports using modern approaches to measure the oxalate content of food [34,35] have opened the possibility of these studies being completed in the near future.

Other nutrients-Several other nutrients have been studied and implicated in the development of stone formation, but several of the associations with risk vary by age, sex or body mass index (BMI). High animal protein intake leads to increased calcium and uric acid excretion as well as decreased urinary citrate [36], all of which increase the risk of stone formation. An increased risk of stone formation was observed for higher animal protein intake only among men with BMI $<25 \mathrm{~kg} / \mathrm{m}^{2}$.[30] A higher intake of sodium[26] or sucrose[27] increases calcium excretion independent of calcium intake, whereas potassium supplementation decreases calcium excretion[29] and many potassium-rich foods increase urinary citrate due to their alkali content. Prospective studies demonstrated sucrose was associated with an increased risk in women $[9,10]$ and higher dietary potassium intake decreased risk in men and older women[7,9,30]. Recently, phytate was also found to reduce substantially the likelihood of stone formation in younger women[10].

Magnesium complexes with oxalate, thereby potentially reducing oxalate absorption in the gastrointestinal tract and decreasing calcium oxalate supersaturation in the urine. A few randomized trials have examined the effect of magnesium supplementation on stone recurrence. However, magnesium was given in combination with other compounds (e.g., thiazide diuretic or potassium citrate) and the dropout rates were high. Currently, it is uncertain whether magnesium supplementation has an independent beneficial effect. In prospective observational studies, higher dietary magnesium was associated with a $30 \%$ lower risk of stone formation in men[30], but not in women[9,10]. 
Vitamin C (ascorbic acid) can be metabolized to oxalate; thus, higher vitamin $\mathrm{C}$ intake could increase the risk of calcium oxalate stone formation. A metabolic trial demonstrated that the consumption of $1000 \mathrm{mg}$ of supplemental vitamin $\mathrm{C}$ twice daily increased urinary oxalate excretion by 22\%[37]. An observational study in men found that those who consumed 1000 mg or more per day of vitamin $\mathrm{C}$ had a $40 \%$ higher risk of stone formation compared to men who consumed less than $90 \mathrm{mg} / \mathrm{day}$ (the recommended dietary allowance)[30]. This relation was observed only after accounting for dietary potassium intake. Although restricting dietary vitamin $\mathrm{C}$ does not seem appropriate (as foods high in vitamin $\mathrm{C}$ are also high in inhibitory factors such as potassium), a calcium oxalate stone former should be encouraged to avoid vitamin $\mathrm{C}$ supplements.

Vitamin B6 is a cofactor in oxalate metabolism, and vitamin B6 deficiency increases oxalate production and urine oxalate excretion. Although high doses of supplemental vitamin B6 may be beneficial role in selected patients with type 1 primary hyperoxaluria, the use of vitamin B6 in other settings remains unclear. Based on observational data, high intake of vitamin B6 may reduce the risk of kidney stone formation in women[38] but not in men[39].

Fluid Intake and Beverages-When the urine output is less than $1 \mathrm{~L} /$ day, risk of stone formation is markedly higher. Observational studies[7,9,10] and a randomized controlled trial [40] have demonstrated the importance of fluid intake in reducing the likelihood of stone formation.

Patients with stone disease often ask what they should and should not drink. Despite previous beliefs to the contrary, observational studies have found that coffee, tea, beer, and wine are associated with a reduced risk of stone formation[41,42]. Although citrus juices theoretically could reduce the risk of stone formation[43], orange juice consumption was not associated with stone formation and grapefruit juice intake was associated with a $40 \%$ higher risk[41,42].

Grapefruit juice is known to have a number of effects on intestinal enzymes, but the mechanism for the observed increased risk is unknown. Previous studies suggested an increased risk for soda consumption and unadjusted results from observational studies also suggested an increased risk. However, after controlling for other dietary components, consumption of soda (with or without caffeine; diet or sugared) was not associated with the risk of stone formation $[41,42]$. Although skim and whole milk were not associated with risk in the observational studies probably because these studies adjusted for the intake of dietary calcium, milk intake likely reduces the risk of calcium kidney stone formation.

\section{Urinary Factors}

The 24-hour urine chemistries provide important prognostic information and direct therapeutic recommendations for prevention. Traditionally, urine results have been categorized into 'normal' and 'abnormal', but recently there has been a greater appreciation of two important points. First, the urine values are continuous so the dichotomization into 'normal' and 'abnormal' is arbitrary and potentially misleading. Second, stone formation is a disorder of concentration, not just the absolute amount excreted. Although terms such as 'hypercalciuria' are often used both clinically and scientifically, the limitations of these terms should be remembered.

Hypercalciuria has been traditionally defined as urine calcium excretion $\geq 300 \mathrm{mg} / \mathrm{day}$ in men and $\geq 250 \mathrm{mg} /$ day in women[44] on a $1000-\mathrm{mg} /$ day calcium diet. Based on these definitions, $\sim 20$ to $40 \%$ of patients with calcium stone disease will have hypercalciuria. Although a higher cutoff value in males makes sense from a calcium balance perspective, it does not for stone formation, particularly given that 24-hour urine volumes are slightly higher in women[45]. 
Hyperoxaluria is defined as urinary oxalate excretion $>45 \mathrm{mg} / \mathrm{d}$. Elevated urinary oxalate excretion may be present in up to $40 \%$ of male stone formers and in up to $10 \%$ in female stone formers[45]. Although mean urinary oxalate levels may not differ between cases and controls, oxalate does appear to be an important independent risk factor for stone formation[45].

The relation between uric acid metabolism and calcium stone disease has been intriguing. Some investigators have reported that hyperuricosuria (defined as greater than $800 \mathrm{mg} / \mathrm{day}$ in men or $750 \mathrm{mg} /$ day in women) is seen more frequently in patients who form calcium stones than normal subjects[46], but others have found no difference[45]. Although allopurinol in a doubleblind trial successfully decreased recurrence rates of calcium stones in patients with hyperuricosuria[14], the role of uric acid in remains unsettled.

Hypocitraturia, typically defined as 24 hour excretion $\leq 320 \mathrm{mg} / \mathrm{d}$, increases risk for stone formation[47] and is found in 5-11\% of first time stone formers[45]. At present, there is insufficient evidence to conclude increasing urinary citrate into the high-normal range provides additional protection.

Low urine volume, for which a variety of definitions have been used, is a common and modifiable risk factor. When defined as 24 hour urine volume less than one liter per day, 12$25 \%$ of first time stone formers will have this abnormality[45]. Observational studies have demonstrated the risk of stone formation decreases with increasing total urine volume[45], and a randomized trial confirmed the value of increasing urine volume[40].

\section{Summary}

Epidemiologic studies have expanded our understanding of stone disease. It is clear that a variety of risk factors contribute to the risk of stone formation and that the importance of these risk factors varies by age and sex. The individual impact of traditional risk factors (e.g. calcium, animal protein) has been quantified and new factors (e.g. body size, phytate) have been identified. Scientifically, results from these studies have forced a reappraisal of our view of risk factors for stone disease. Importantly, the results from epidemiologic studies can be applied in the clinical setting with the goal of reducing the likelihood of stone formation.

\section{Acknowledgments}

This work was supported by grant DK59583 from the National Institutes of Health.

\section{References}

1. Johnson CM, Wilson DM, O'Fallon WM, Malek RS, Kurland LT. Renal stone epidemiology: a 25year study in Rochester, Minnesota. Kidney Int 1979;16(5):624-31. [PubMed: 548606]

2. Stamatelou KK, Francis ME, Jones CA, Nyberg LM, Curhan GC. Time trends in reported prevalence of kidney stones in the United States: 1976-1994. Kidney Int 2003;63(5):1817-23. [PubMed: 12675858]

3. Yoshida O, Okada Y. Epidemiology of urolithiasis in Japan: a chronological and geographical study. Urologia Internationalis 1990;45:104-111. [PubMed: 2330656]

4. Hesse A, Brandle E, Wilbert D, Kohrmann KU, Alken P. Study on the prevalence and incidence of urolithiasis in Germany comparing the years 1979 vs 2000. Eur Urol 2003;44(6):709-13. [PubMed: 14644124]

5. Soucie JM, Thun MJ, Coates RJ, McClellan W, Austin H. Demographic and geographic variability of kidney stones in the United States. Kidney Int 1994;46(3):893-9. [PubMed: 7996811]

6. Soucie J, Coates R, McClellan W, Austin H, Thun M. Relation between geographic variability in kidney stones prevalence and risk factors for stones. Am J Epidemiol 1996;143:487-495. [PubMed: 8610664] 
7. Curhan GC, Willett WC, Rimm EB, Stampfer MJ. A prospective study of dietary calcium and other nutrients and the risk of symptomatic kidney stones. N Engl J Med 1993;328:833-838. [PubMed: 8441427]

8. Hiatt RA, Dales LG, Friedman GD, Hunkeler EM. Frequency of urolithiasis in a prepaid medical care program. Am J Epidemiol 1982;115:255-265. [PubMed: 7058784]

9. Curhan G, Willett W, Speizer F, Spiegelman D, Stampfer M. Comparison of dietary calcium with supplemental calcium and other nutrients as factors affecting the risk for kidney stones in women. Ann Intern Med 1997;126:497-504. [PubMed: 9092314]

10. Curhan GC, Willett WC, Knight EL, Stampfer MJ. Dietary factors and the risk of incident kidney stones in younger women (Nurses' Health Study II). Arch Intern Med 2004;164:885-891. [PubMed: 15111375]

11. Lieske JC, Pena de la Vega LS, Slezak JM, Bergstralh EJ, Leibson CL, Ho KL, et al. Renal stone epidemiology in Rochester, Minnesota: an update. Kidney Int 2006;69(4):760-4. [PubMed: 16518332]

12. Borghi L, Schianchi T, Meschi T, Guerra A, Allegri F, Maggiore U, et al. Comparison of two diets for the prevention of recurrent stones in idiopathic hypercalciuria. N Engl J Med 2002;346(2):7784. [PubMed: 11784873]

13. Ettinger B, Pak CY, Citron JT, Thomas C, Adams-Huet B, Vangessel A. Potassium-magnesium citrate is an effective prophylaxis against recurrent calcium oxalate nephrolithiasis. J Urol 1997;158(6): 2069-73. [PubMed: 9366314]

14. Ettinger B, Tang A, Citron JT, Livermore B, Williams T. Randomized trial of allopurinol in the prevention of calcium oxalate calculi. N Engl J Med 1986;315(22):1386-9. [PubMed: 3534570]

15. Ettinger B, Citron JT, Livermore B, Dolman LI. Chlorthalidone reduces calcium oxalate calculous recurrence but magnesium hydroxide does not. J Urol 1988;139(4):679-84. [PubMed: 3280829]

16. Curhan G, Willett W, Rimm E, Stampfer M. Family history and risk of kidney stones. J Am Soc Nephrol 1997;8:1568-1573. [PubMed: 9335385]

17. Resnick M, Pridgen DB, Goodman HO. Genetic predisposition to formation of calcium oxalate renal calculi. N Engl J Med 1968;278(24):1313-8. [PubMed: 5648597]

18. D'Angelo A, Calo L, Cantaro S, Giannini S. Calciotropic hormones and nephrolithiasis. Miner Electrolyte Metab 1997;23(3-6):269-72. [PubMed: 9387131]

19. Taylor EN, Stampfer MJ, Curhan GC. Obesity, weight gain, and the risk of kidney stones. Jama 2005;293(4):455-62. [PubMed: 15671430]

20. Kramer HM, Curhan G. The association between gout and nephrolithiasis: the National Health and Nutrition Examination Survey III, 1988-1994. Am J Kidney Dis 2002;40(1):37-42. [PubMed: 12087559]

21. Kramer HJ, Choi HK, Atkinson K, Stampfer M, Curhan GC. The association between gout and nephrolithiasis in men: The Health Professionals' Follow-Up Study. Kidney Int 2003;64(3):10226. [PubMed: 12911552]

22. Taylor EN, Stampfer MJ, Curhan GC. Diabetes mellitus and the risk of nephrolithiasis. Kidney Int 2005;68(3):1230-5. [PubMed: 16105055]

23. Atan L, Andreoni C, Ortiz V, Silva EK, Pitta R, Atan F, et al. High kidney stone risk in men working in steel industry at hot temperatures. Urology 2005;65(5):858-61. [PubMed: 15882711]

24. Robertson WG, Peacock M, Hodgkinson A. Dietary changes and the incidence of urinary calculi in the U.K. between 1958 and 1976. J Chron Dis 1979;32:469-476. [PubMed: 457831]

25. Larsson L, Tiselius HG. Hyperoxaluria. Miner Electrolyte Metab 1987;13(4):242-50. [PubMed: 3306316]

26. Muldowney FP, Freaney R, Moloney MF. Importance of dietary sodium in the hypercalciuria syndrome. Kidney International 1982;22:292-296. [PubMed: 7176331]

27. Lemann J Jr, Piering WF, Lennon EJ. Possible role of carbohydrate-induced calciuria in calcium oxalate kidney-stone formation. N Engl J Med 1969;280(5):232-7. [PubMed: 5818178]

28. Johansson G, Backman U, Danielson BG, Fellstrom B, Ljunghall S, Wikstrom B. Biochemical and clinical effects of the prophylactic treatment of renal calcium stones with magnesium hydroxide. $\mathrm{J}$ Urol 1980;124:770-774. [PubMed: 7441826] 
29. Lemann J Jr, Pleuss JA, Gray RW, Hoffmann RG. Potassium administration reduces and potassium deprivation increases urinary calcium excretion in healthy adults [corrected]. Kidney Int 1991;39(5): 973-83. [PubMed: 1648646]

30. Taylor EN, Stampfer MJ, Curhan GC. Dietary factors and the risk of incident kidney stones in men: new insights after 14 years of follow-up. J Am Soc Nephrol 2004;15(12):3225-32. [PubMed: 15579526]

31. Bataille P, Charransol G, Gregoire I, Daigre JL, Coevoet B, Makdassi R, et al. Effect of calcium restriction on renal excretion of oxalate and the probability of stones in the various pathophysiological groups with calcium stones. J Urol 1983;130(2):218-23. [PubMed: 6876264]

32. Jackson RD, LaCroix AZ, Gass M, Wallace RB, Robbins J, Lewis CE, et al. Calcium plus vitamin D supplementation and the risk of fractures. NEngl J Med 2006;354(7):669-83. [PubMed: 16481635]

33. Holmes RP, Assimos DG. The impact of dietary oxalate on kidney stone formation. Urol Res 2004;32 (5):311-6. [PubMed: 15221245]

34. Siener R, Honow R, Voss S, Seidler A, Hesse A. Oxalate content of cereals and cereal products. J Agric Food Chem 2006;54(8):3008-11. [PubMed: 16608223]

35. Holmes R, Kennedy M. Estimation of the oxalate content of foods and daily oxalate intake. Kidney Int 2000;57:1662-1667. [PubMed: 10760101]

36. Breslau N, Brinkely L, Hill K, Pak C. Relationship of animal protein-rich diet to kidney stone formation and calcium metabolism. J Clin Endocrinol Metab 1988;66:140-146. [PubMed: 2826524]

37. Traxer O, Huet B, Poindexter J, Pak CY, Pearle MS. Effect of ascorbic acid consumption on urinary stone risk factors. J Urol 2003;170(2 Pt 1):397-401. [PubMed: 12853784]

38. Curhan GC, Willett WC, Speizer FE, Stampfer MJ. Intake of vitamins B6 and C and the risk of kidney stones in women. J Am Soc Nephrol 1999;10(4):840-5. [PubMed: 10203369]

39. Curhan GC, Willett WC, Rimm EB, Stampfer MJ. A prospective study of the intake of vitamins C and B6, and the risk of kidney stones in men. J Urol 1996;155(6):1847-51. [PubMed: 8618271]

40. Borghi L, Meschi T, Amato F, Briganti A, Novarini A, Giannini A. Urinary volume, water and recurrences in idiopathic calcium nephrolithiasis: a 5-year randomized prospective study. J Urol 1996;155:839-843. [PubMed: 8583588]

41. Curhan GC, Willett WC, Rimm EB, Spiegelman D, Stampfer MJ. Prospective study of beverage use and the risk of kidney stones. Am J Epidemiol 1996;143(3):240-7. [PubMed: 8561157]

42. Curhan GC, Willett WC, Speizer FE, Stampfer MJ. Beverage use and risk for kidney stones in women. Ann Intern Med 1998;128(7):534-40. [PubMed: 9518397]

43. Wabner C, Pak C. Effect of orange juice consumption on urinary stone risk factors. J Urol 1993;149:1405-1409. [PubMed: 8501777]

44. Hodgkinson A, Pyrah LN. The urinary excretion of calcium and inorganic phosphate in 344 patients with calcium stone of renal origin. Br J Surg 1958;46(195):10-8. [PubMed: 13572812]

45. Curhan GC, Willett WC, Speizer FE, Stampfer MJ. Twenty-four-hour urine chemistries and the risk of kidney stones among women and men. Kidney Int 2001;59(6):2290-8. [PubMed: 11380833]

46. Coe FL. Hyperuricosuric calcium oxalate nephrolithiasis. Kidney Int 1978;13(5):418-26. [PubMed: 661071]

47. Pak CY. Citrate and renal calculi: an update. Miner Electrolyte Metab 1994;20(6):371-7. [PubMed: 7783699] 


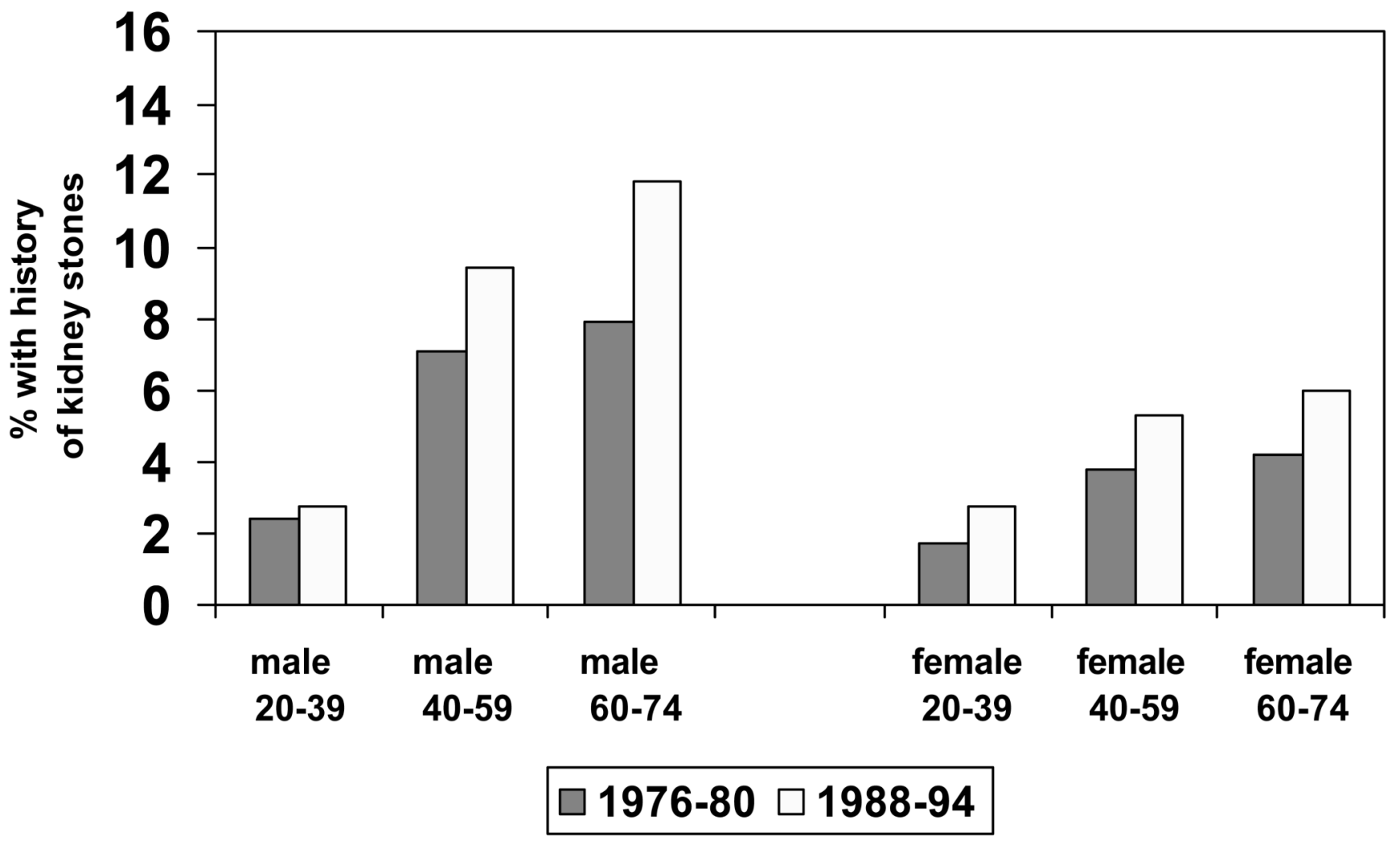

Adapted from reference 2 .

Figure 1.

Prevalence of stone disease by sex and age 


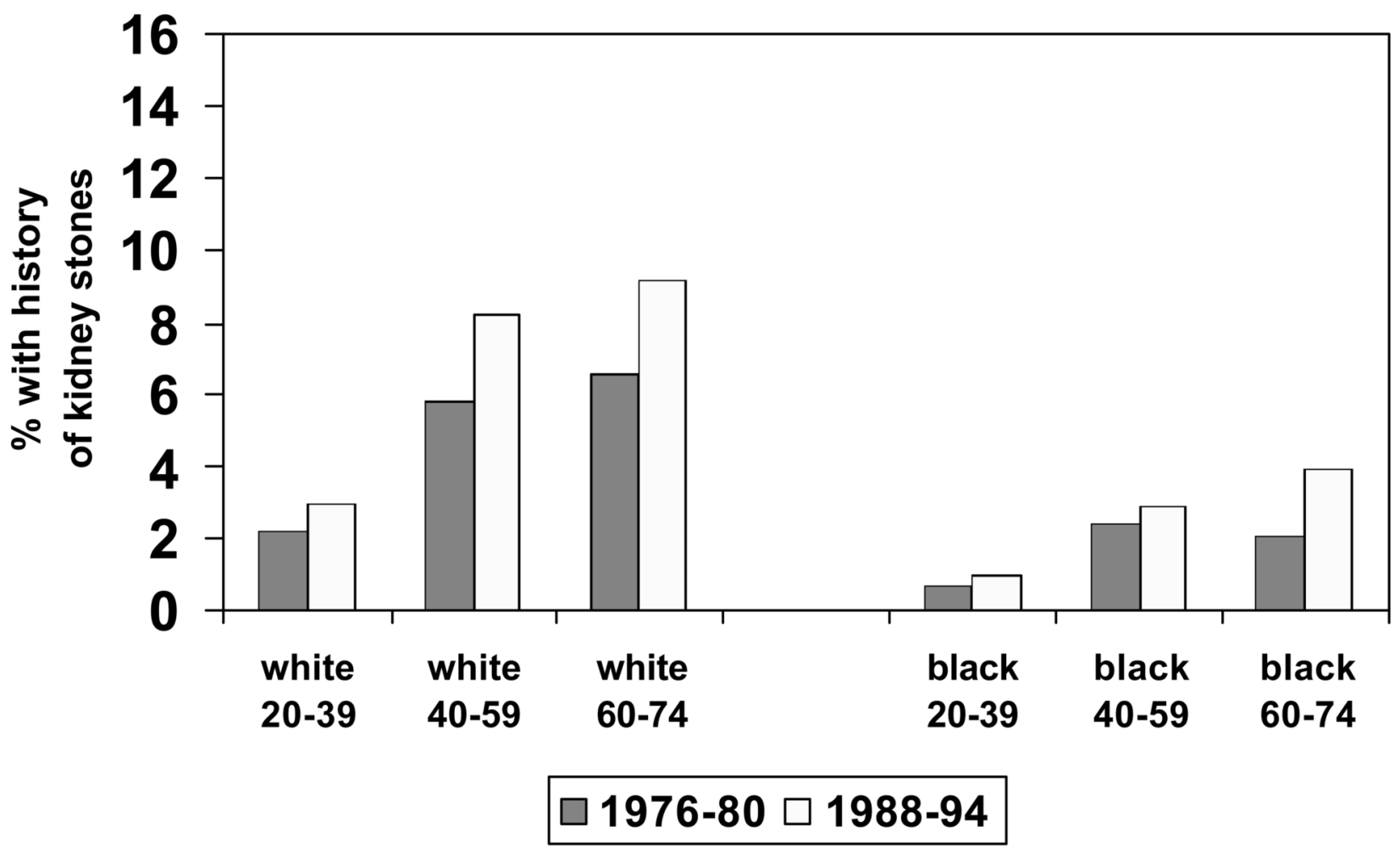

\section{Adapted from reference 2.}

Figure 2.

Prevalence of stone disease by race and age 